\title{
Approaches to Teaching in Professional Training: a Qualitative Study
}

\section{Caroline Bonnes $^{1}$ (D) $\cdot$ Sabine Hochholdinger ${ }^{1}$ (D)}

Received: 29 November 2018 / Accepted: 19 February 2020/ Published online: 4 April 2020

C) The Author(s) 2020

\begin{abstract}
Teaching approaches have been shown to be an important aspect of teaching in school or higher education. Although differing approaches to teaching may play a role in the outcome of professional trainings, they have not yet been further studied in this context. It is first necessary to determine whether the existing approaches to teaching construct can be transferred to the context of professional training and how approaches to teaching can be operationalized for future studies. For a multi-perspective view, we conducted 45 interviews with trainers, human resource development practitioners and trainees. The interviews were analyzed by qualitative content analysis. Our results show that the construct can be transferred to professional training. However, to apply the approaches to teaching construct to professional training, some of the underlying categories must be modified. Furthermore, we discuss the need to include new aspects, such as the category of transfer. Implications for further research are presented, including the development of a measurement instrument based on the results.
\end{abstract}

Keywords Approaches to teaching $\cdot$ Professional training $\cdot$ Trainers $\cdot$ Transfer

\section{Introduction}

The role of the trainer within professional training is a significant factor impacting training outcomes (Burke and Hutchins 2008; Baldwin et al. 2017), such as the transfer outcome, i.e., the ability of trainees to apply what they have learned to their workplace setting. However, the role of the trainer has been widely neglected in empirical studies. Several authors have summarized important factors for transfer facilitation (Baldwin and Ford

Caroline Bonnes

caroline.bonnes@uni-konstanz.de

Sabine Hochholdinger

sabine.hochholdinger@uni-konstanz.de

1 Department of Economics, University of Konstanz, Universitaetsstr. 10, 78457 Constance, Germany 
1988; Blume et al. 2010; Salas et al. 2012), such as trainee characteristics, training design and work environment, but little attention has been given to the role of trainers and their approaches to teaching. Differing approaches to teaching impact learner outcomes and constitute an important part of the interaction between learner and instructor (e.g., Trigwell et al. 1999; Trigwell and Prosser 2004; Braun and Hannover 2008; Rosário et al. 2014). Therefore, the teaching approach may influence how trainers design and implement their training and could thereby affect the transfer outcome of the training.

To date, approaches to teaching have been studied almost exclusively in the learning settings of school or higher education. However, as the learning setting of professional training is similar to that of classrooms, the trainers' approaches to teaching may also play an important role in the learning and transfer outcomes of trainees. To date, there has been no measurement instrument to study the relationship between approaches to teaching and training outcome in the context of professional training. Thus, the goal of this study is to investigate whether the concept of approaches to teaching is applicable to professional training and to identify and delineate necessary changes for the use and operationalization of the construct in future research on training transfer.

We first introduce the concept of approaches to teaching as it was conceptualized in the higher education context by Trigwell et al. in 1994 and present empirical evidence for the relevance of approaches to teaching for instructional design and learning outcomes. We then describe the professional training context and discuss its possible differences from the higher education context to derive our research objectives.

\section{Approaches to Teaching}

Approaches to teaching were conceptualized by Trigwell et al. (1994) as combinations of different intentions and strategies that correspond with five different approaches to teaching (see Table 1). The model is based on a qualitative phenomenological study with 24 university teachers of chemistry and physics (Trigwell et al. 1994). Trigwell et al. (1994) describe four different intentions to be understood in hierarchical order: information transmission, concept acquisition, conceptual development and conceptual change. While information transmission describes the aim to merely transmit information to the students, concept acquisition aims for the students to acquire the concepts of the discipline as well as the concepts' relationships with one another, thus promoting a deeper understanding of the concepts. Conceptual development does not view students as passive recipients of knowledge, but rather aims for the students to construct their own knowledge and to develop it further within already existing conceptions of the discipline. Conceptual change refers to students confronting and qualitatively changing their conceptions of a phenomenon, and thus implies that the prior conceptions of the students are not consistent with those of the discipline and thus need to be reconstructed and changed.

Strategies are divided into three different types: teacher-focused, student/teacher interaction and student-focused. A teacher-focused or transmissive strategy could be characterized as being focused on the content, in which the teacher plays the role of an expert and mostly uses transmissive methods through which the students passively receive the content. In contrast, a student-focused or constructivist strategy could be characterized as placing the learner in the center of the teaching process and the teacher in the role of a learning guide, who uses constructivist methods and enables the students to participate actively in the learning process. While teacher-focused and student-focused strategies 
Table 1 Approaches to teaching

\begin{tabular}{llll}
\hline Intention & Strategy & & \\
\cline { 2 - 4 } & Teacher-focused & Student/Teacher interaction & Student-focused \\
\hline Information transmission & $\mathrm{A}$ & & \\
Concept acquisition & $\mathrm{B}$ & $\mathrm{C}$ & $\mathrm{D}$ \\
Conceptual development & & & $\mathrm{E}$ \\
Conceptual change & & & \\
\hline
\end{tabular}

Reprinted by permission from Springer Nature: Springer Nature, Higher Education, Qualitative differences in approaches to teaching first year university science, Trigwell et al., Copyright (1994)

place either teachers or students at the center of the learning setting, student/teacher interaction describes strategies that include both teacher and students being (inter) active, for example, the teacher asking questions to the students (Trigwell et al. 1994).

Combining different intentions and strategies leads to five different approaches to teaching, from approach A to approach E (see Table 1). Based on this model, Trigwell and Prosser (2004) developed the Approaches to Teaching Inventory (ATI), which has been widely used within the context of higher education (e.g., Lindblom-Ylänne et al. 2006; Postareff et al. 2008; Fendler and Gläser-Zikuda 2013; Könings et al. 2014; Stes and van Petegem 2014).

We consider approaches to teaching to be a valuable concept to be further studied in professional training. The concept is theoretically placed between the concept of teachers' beliefs and observable teaching action. Beliefs are mental representations, e.g. on subjective theories on teaching and learning (Baumert and Kunter 2013). Kember (1997) proposes that these subjective conceptions might influence approaches to teaching. Braun and Hannover (2008) found that approaches to teaching in turn are related to teaching action, with teachers adopting a constructivist approach using more activating methods. However, research has shown that teaching beliefs are not consistently in line with teaching actions (e.g., Murray and Macdonald 1997). Approaches to teaching could constitute the missing link between beliefs on teaching and observable teaching action and, thus, could be a better predictor of teaching action. The combination of intention and strategy provides the opportunity to study the different kinds of actions trainers take during training and to simultaneously pursue the question of what objectives trainers aim to achieve with their actions. The study of approaches to teaching is thus more action-oriented, while including the underlying motivations of the trainers for designing and conducting their training the way they do.

\section{Relevance for Learning Outcomes and Instructional Design}

In addition to the potential of the theoretical framework, further investigating approaches to teaching in the context of professional training appears very promising because studies in the last two decades have shown evidence that the teaching approach is significantly related to student learning outcomes and instructional design. 
Fendler and Brauer (2013) studied the relationship of approaches to teaching to three components of teaching as rated by students: learning support, appropriate use of methods and goal orientation. They found that students' positive evaluation of teaching methods correlated positively with a student-focused approach and negatively with a teacher-focused approach. The same results were found for the quality of learning support. However, they found no correlation between goal orientation and any of the teaching approaches.

The only study that has examined approaches to teaching in the context of professional training was conducted by Hochholdinger and Keller (2015), who demonstrated that a constructivist approach is positively correlated with positive emotional reactions and evaluations by trainees. Furthermore, trainers with a constructivist approach used more activating methods.

With respect to students' learning outcomes, a constructivist approach was related to more significant increases in competence as perceived by students (Braun and Hannover 2008) and to a deep learning approach (Trigwell et al. 1999; Trigwell and Prosser 2004; Rosário et al. 2014) as opposed to a surface approach. Uiboleht et al. $(2018,2019)$ explored in their qualitative multi-case study the effects of consonant and dissonant approaches to teaching. Consonant approaches to teaching imply the systematic use of either a teacher-focused or student-focused approach. A dissonant approach would include using elements from both approaches. They found that a consonant student-oriented approach was related to a positive perception of the teaching-learning environment while a dissonant approach was related to perceiving the teaching-learning environment as hindering (Uiboleht et al. 2019). Similarly, students' learning outcomes and approaches to learning were to some degree higher compared to a dissonant approach, although the relationship between a dissonant approach and a lower quality of learning outcomes and approaches to teaching did not emerge systematically throughout the data (Uiboleht et al. 2018).

\section{Transferring the Concept to Professional Training}

Approaches to teaching have been conceptualized in the higher education context. This concept origin is reflected in the descriptions of the different approaches using phrases such as "transmitting to the students information about the discipline" or "gain disciplinary knowledge". Additionally, if we look at the items of the ATI (Trigwell and Prosser 2004), they include items with a strong reference to higher education, such as "I structure this subject to help students to pass the formal assessment items."

Professional training refers to planned and systematic activities that facilitate the acquisition of knowledge, skills, and attitudes (Salas et al. 2012) that relate to the work life of trainees. Laker and Powell (2011) differentiate between so called hard-skill trainings and soft-skill trainings. Hard-skill trainings have a technical focus, e.g., trainings on law or software, and soft-skill trainings have a more intra- or interpersonal focus, e.g., trainings on communication or leadership. Professional training has two main outcome goals. The first goal is to promote learning in the sense of acquiring new knowledge and behavior (Salas et al. 2012). The second goal is to promote transfer, which means trainees are able to transfer the new knowledge and behavior into their workplace and eventually improve their job performance. 
Although the didactical settings of training and higher education might be similar, from lectures to seminars to blended learning settings or the use of e-learning, the primary goals are different. Courses in higher education pursue the education of an individual on a specific theme within the studied subject, mostly followed by some sort of formal assessment. Professional training has a stronger focus on training than on education, and the primary goal is to enable the trainee to transfer his or her knowledge to the workplace.

Therefore, we argue that before applying the concept of approaches to teaching to the context of professional training, there is the need to first investigate whether the model can be transferred and whether it needs context-specific modifications.

\section{Research Objectives}

Our literature review suggested that the approaches to teaching model is a promising construct to be further researched in the context of professional training. Therefore, we aimed to investigate whether the approaches to teaching model as conceptualized in theory is applicable in the field of professional training and to determine whether any context-specific modification is necessary. Additionally, we explored how the individual aspects of intentions and strategies can be described in context-specific ways to operationalize the construct in future studies.

\section{Method}

Based on our research objectives, the second of which is explorative in nature, we chose a qualitative approach to our research question by conducting semistructured interviews. It was important for us to study more than only what the trainers themselves said about intentions and strategies in training. To capture all aspects of approaches to teaching in professional training, we integrated multiple perspectives into our study by including both the trainees of professional trainings and the human resource development (HRD) practitioners responsible in companies for developing concepts for trainings and selecting trainers. While HRD practitioners have an expert outside view, trainees, as participants of professional training, can contribute their inside view that might complement the perspectives of the training professionals. Therefore, every group brings their own kind of expert knowledge regarding training as well as regarding possible approaches to teaching during a training session. Hence, our data do not exclusively reflect the approaches to teaching expressed by individual trainers but represent multi-perspective perceptions of what kind of approaches to teaching exist in professional training and how these intentions and strategies can be further described within this context. In the following section, we describe our study design and provide information on our sample. We then introduce the method we used for data analysis and describe the process for developing our category system.

\section{Study Design and Sample}

We used a semistructured interview guideline that was part of a larger research project on the professional competence of trainers, their career paths, and their ways of 
acquiring the necessary qualifications and competencies for working as a trainer. Sociodemographic data were collected using a separate questionnaire for each group asking for age and job experience. The study was conducted in Germany.

The results presented here mainly refer to the answers to the following interview questions: "What is an ideal trainer for you?", "What is a nonideal trainer for you?", "What is an ideal training for you?", and "What is a nonideal training for you?". Following the principle of openness in qualitative research, we decided to ask broad open questions instead of specific questions, e.g., asking specifically about strategies. Although the interviewers had the interview guideline, each interview was conducted in a way that allowed the interviewer to flexibly follow his or her interview partner to develop a natural conversation regarding these topics, while still focusing on the main themes included in the interview guideline. Consequently, aspects referring to the theme of approaches to teaching could come up in different parts of the interview. Therefore, the entire interview texts were included in the analysis.

All interviewers received interviewer training. Some interviews were conducted face-to-face, but most were conducted by telephone. The subjects were contacted through trainer networks, professional networks, and educational institutions, which distributed our request via newsletter. Interview lengths differed among the different groups due to the varying number of additional group-specific questions. Interviews with trainers had an average duration of $39 \mathrm{~min}$; interviews with HRD practitioners, $22 \mathrm{~min}$; and interviews with trainees, $10 \mathrm{~min}$.

We interviewed 23 trainers, 12 trainees and 10 HRD practitioners $(N=45)$. Of the 23 trainers, 13 were soft-skill trainers (e.g., conducting leadership or time management trainings), 4 were hard-skill trainers (e.g., conducting trainings on law or management themes), and 6 offered both types of trainings. On average, the trainers were 34.7 years old and had 16.2 years of work experience as trainers (see Table 2). The majority $(60.9 \%)$ indicated that their main profession was being a trainer. The other trainers were either working as trainers outside of their main occupation $(26.1 \%)$ or not regularly $(4.3 \%)$. The data for two participants are missing. Approximately one-third (34.8\%) have a university degree related to education or psychology. The trainees were 34.7 years old on average. The mean age of the HRD practitioners was 38.7 years, and their mean length of service in human resource development was 11.2 years. The gender ratio was balanced in all three groups (see Table 3). The sociodemographic figures underline the range of variance in the sample, which allowed us to capture a broad perspective on approaches to teaching.

\section{Data Analysis and Development of the Category System}

The interviews were transcribed and analyzed by qualitative content analysis (Mayring 2014) using the software MAXQDA 12. Qualitative content analysis is a qualitative analysis tool that allows for the identification of specific content from within a broad qualitative dataset and the structuring and summarizing of the content. In line with our research objectives, we combined a deductive and inductive approach by using nominal deductive category assignment and inductive category formation (Mayring 2014). Both approaches will be further described below.

The basic structure of our category system was deductively drawn from the conceptualization of approaches to teaching by Trigwell et al. (1994) to investigate whether the 
Table 2 Age, job experience, and training experience

\begin{tabular}{|c|c|c|c|c|}
\hline & $\mathrm{M}$ & SD & Min & Max \\
\hline \multicolumn{5}{|l|}{ Age (in years) } \\
\hline Trainers & 45.7 & 7.9 & 28 & 56 \\
\hline HRD practitioners & 38.7 & 9.3 & 28 & 56 \\
\hline Trainees & 34.7 & 10.3 & 24 & 54 \\
\hline \multicolumn{5}{|l|}{ Job experience (in years) } \\
\hline Trainers & 16.2 & 8.4 & 1 & 28 \\
\hline HRD practitioners & 11.2 & 8.2 & 3 & 27 \\
\hline Number of trainings attended by trainees & 18.3 & 10.6 & 5 & 45 \\
\hline
\end{tabular}

conceptualization is applicable to professional training. The two main categories of intention and strategy were used, along with the according subcategories of the model (see Table 1).

To be open to possible context-specific modifications, we used an inductive approach and included emerging categories into the system. Hence, we subsequently added the intention category transfer and the strategy category transfer-facilitating, which were inductively deduced as an emergent theme from the material. While coding the material within the project team, we found statements in the text that referred to the definition of intentions that could not be distinctly allocated to one of the subcategories by Trigwell et al. (1994). The statements were discussed and eventually identified as forming a new subcategory labeled transfer under the category of intention. Simultaneously, we found statements referring to strategies that were explicitly used to facilitate transfer or could be implicitly related to facilitating transfer based on what we know from the literature on training transfer (e.g., Burke and Hutchins 2007; Grossman and Salas 2011; Salas et al. 2012). The two categories were added to the overall category system. The structure of the final category system with its main categories and corresponding category definitions is shown in Table 4.

Similarly, we used an inductive approach to develop subcategories to describe, for example, how the category "constructivist strategies" can be operationalized in professional training. Categories were only differentiated into further subcategories when clearly discriminable subthemes could be identified. The subcategories were developed from the material in an inductive, iterative process within the research team and were formed by clustering all codings of similar content into a new category. During the

Table 3 Gender distribution

\begin{tabular}{|c|c|c|c|c|}
\hline & \multicolumn{2}{|l|}{$\mathrm{m}$} & \multicolumn{2}{|l|}{$\mathrm{f}$} \\
\hline & $\mathrm{n}$ & $\%$ & $\mathrm{n}$ & $\%$ \\
\hline Trainers & 13 & 56.5 & 10 & 43.5 \\
\hline HRD practitioners & 6 & 60.0 & 4 & 40.0 \\
\hline Trainees & 6 & 50.0 & 6 & 50.0 \\
\hline Total & 25 & 55.6 & 20 & 44.4 \\
\hline
\end{tabular}


Table 4 Category system

\begin{tabular}{|c|c|c|}
\hline Category & Definition & Examples \\
\hline Intention & $\begin{array}{l}\text { Provides justification for the use of a } \\
\text { strategy or describes what kind of goal } \\
\text { is to be achieved during training }\end{array}$ & \\
\hline $\begin{array}{l}\text { Information } \\
\text { transmission }\end{array}$ & $\begin{array}{l}\text { Teacher-oriented intention, pursuing the } \\
\text { dissemination of knowledge }\end{array}$ & $\begin{array}{l}\text { "when I want to impart knowledge," "to } \\
\text { be able to pass on the knowledge to } \\
\text { others," "the expertise he wants to } \\
\text { convey" }\end{array}$ \\
\hline Concept acquisition & $\begin{array}{l}\text { Teacher-oriented intention, pursuing not } \\
\text { only the transmission of knowledge } \\
\text { but also the understanding of the } \\
\text { knowledge on a deeper level }\end{array}$ & $\begin{array}{l}\text { "to activate the need to really understand } \\
\text { something," "to explain something in } \\
\text { such a way that it is understandable to } \\
\text { others" }\end{array}$ \\
\hline $\begin{array}{l}\text { Conceptual } \\
\text { development }\end{array}$ & $\begin{array}{l}\text { Learner-oriented intention, pursuing } \\
\text { knowledge that is accumulated by the } \\
\text { learner in a self-directed learning pro- } \\
\text { cess initiated by the learner }\end{array}$ & $\begin{array}{l}\text { "learners find solutions by themselves," } \\
\text { "learners should have the opportunity } \\
\text { to acquire knowledge by themselves" }\end{array}$ \\
\hline Conceptual change & $\begin{array}{l}\text { Learner-oriented intentions, pursuing the } \\
\text { learner's incorporation of the imparted } \\
\text { knowledge in a deeper process of } \\
\text { change that goes beyond the } \\
\text { knowledge imparted in the training }\end{array}$ & $\begin{array}{l}\text { "development of personality," "change of } \\
\text { behavior" }\end{array}$ \\
\hline Transfer & $\begin{array}{l}\text { Learner-oriented intention, pursuing the } \\
\text { facilitation and enabling the transfer of } \\
\text { the acquired knowledge into (working) } \\
\text { practice }\end{array}$ & $\begin{array}{l}\text { "to work sustainably so that it is really } \\
\text { transferable to practice," "to secure } \\
\text { learning transfer" }\end{array}$ \\
\hline Strategy & $\begin{array}{l}\text { The means by which the training is } \\
\text { designed and conducted, including the } \\
\text { methods }\end{array}$ & \\
\hline Transmissive & $\begin{array}{l}\text { Strategy that is teacher-oriented and fo- } \\
\text { cuses on imparting knowledge from a } \\
\text { teacher-centric viewpoint }\end{array}$ & $\begin{array}{l}\text { "Power Point presentations," "I give } \\
\text { input", "not caring about the learners' } \\
\text { reactions," "I am the expert," "little to } \\
\text { no learner activation" }\end{array}$ \\
\hline Interactive & $\begin{array}{l}\text { Strategy that is based on an interaction } \\
\text { between the trainer and the learner }\end{array}$ & $\begin{array}{l}\text { "work interactively with the class," } \\
\text { "talking with the learners in the class } \\
\text { about things" }\end{array}$ \\
\hline Constructivist & $\begin{array}{l}\text { Strategy that is learner-oriented and fo- } \\
\text { cuses on providing learning opportu- } \\
\text { nities in which the learner can } \\
\text { self-directedly construct knowledge. }\end{array}$ & $\begin{array}{l}\text { "to adjust to the learners needs," } \\
\text { "roleplaying," "to try things out," "I } \\
\text { become a learning guide," "phases of } \\
\text { self-reflection," "you should give the } \\
\text { learners room to acquire knowledge } \\
\text { by themselves" }\end{array}$ \\
\hline Transfer-facilitating & $\begin{array}{l}\text { Strategy that facilitates or enables the } \\
\text { transfer of the acquired knowledge } \\
\text { into (working) practice }\end{array}$ & $\begin{array}{l}\text { "to create measurements for transfer," } \\
\text { "reflection on their own practice," } \\
\text { "opportunities for exercises within the } \\
\text { training," "to give good feedback" }\end{array}$ \\
\hline
\end{tabular}

research process, the category names and the structure of the subcategory system were constantly evaluated and modified when necessary. The five intention categories were not divided into further subcategories because no distinct subthemes evolved during the analysis. However, all strategy categories could be divided into two to six specific 
Table 5 Intention: Frequency of reported intention categories

\begin{tabular}{|c|c|c|c|c|c|c|c|c|}
\hline & \multicolumn{2}{|c|}{ Total } & \multicolumn{2}{|c|}{ Trainers } & \multicolumn{2}{|c|}{ Practitioners } & \multicolumn{2}{|c|}{ Trainees } \\
\hline & $\mathrm{n}$ & $\%$ & $\mathrm{n}$ & $\%$ & $\mathrm{n}$ & $\%$ & $\mathrm{n}$ & $\%$ \\
\hline Information transmission & 71 & 30.6 & 51 & 29.7 & 12 & 27.9 & 8 & 47.1 \\
\hline Concept acquisition & 32 & 13.8 & 24 & 14.0 & 5 & 11.6 & 3 & 17.6 \\
\hline Conceptual development & 28 & 12.1 & 20 & 11.6 & 4 & 9.3 & 4 & 23.5 \\
\hline Conceptual change & 26 & 11.2 & 19 & 11.0 & 7 & 16.3 & 0 & 0.0 \\
\hline Transfer & 75 & 32.3 & 58 & 33.7 & 15 & 34.9 & 2 & 11.8 \\
\hline Total & 232 & 100.0 & 172 & 100.0 & 43 & 100.0 & 17 & 100.0 \\
\hline
\end{tabular}

Table 6 Strategy: Frequencies of main categories and their subcategories

\begin{tabular}{|c|c|c|c|c|c|c|c|c|}
\hline & \multicolumn{2}{|l|}{ Total } & \multicolumn{2}{|c|}{ Trainers } & \multicolumn{2}{|c|}{ Practitioners } & \multicolumn{2}{|c|}{ Trainees } \\
\hline & $\mathrm{n}$ & $\%$ & $\mathrm{n}$ & $\%$ & $\mathrm{n}$ & $\%$ & $\mathrm{n}$ & $\%$ \\
\hline Transmissive & 366 & 31.2 & 230 & 19.6 & 72 & 6.1 & 64 & 5.5 \\
\hline Transmissive methods & 158 & 43.2 & 103 & 44.8 & 26 & 36.1 & 29 & 45.3 \\
\hline Imparting knowledge & 95 & 26.0 & 54 & 23.5 & 23 & 31.9 & 18 & 28.1 \\
\hline Negative learner-orientation & 57 & 15.6 & 34 & 14.8 & 15 & 20.8 & 8 & 12.5 \\
\hline Trainer takes center stage as an expert & 36 & 9.8 & 29 & 12.6 & 6 & 8.3 & 1 & 1.6 \\
\hline No activating methods & 20 & 5.5 & 10 & 4.3 & 2 & 2.8 & 8 & 12.5 \\
\hline Interactive & 106 & 9.0 & 65 & 61.3 & 16 & 15.1 & 25 & 23.6 \\
\hline Interactive methods & 83 & 78.3 & 52 & 80.0 & 9 & 56.3 & 22 & 88.0 \\
\hline Interactive teaching action & 23 & 21.7 & 13 & 12.3 & 7 & 43.8 & 3 & 12.0 \\
\hline Constructivist & 459 & 39.2 & 327 & 71.2 & 77 & 16.8 & 55 & 12.0 \\
\hline Constructivist methods & 168 & 36.6 & 112 & 34.3 & 26 & 33.8 & 30 & 54.5 \\
\hline Learner-orientation & 165 & 35.9 & 120 & 36.7 & 33 & 42.9 & 12 & 21.8 \\
\hline Active learning & 53 & 11.5 & 36 & 11.0 & 9 & 11.7 & 8 & 14.5 \\
\hline Trainer as learning guide & 28 & 6.1 & 23 & 7.0 & 4 & 5.2 & 1 & 1.8 \\
\hline Self-reflection & 23 & 5.0 & 21 & 6.4 & 2 & 2.6 & 0 & 0.0 \\
\hline $\begin{array}{l}\text { Independently develop and acquire knowledge and } \\
\text { solutions }\end{array}$ & 22 & 4.8 & 15 & 4.6 & 3 & 3.9 & 4 & 7.3 \\
\hline Transfer-facilitating & 241 & 20.6 & 184 & 76.3 & 25 & 10.4 & 32 & 13.3 \\
\hline Transfer-enabling methods & 86 & 35.7 & 62 & 33.7 & 10 & 40.0 & 14 & 43.8 \\
\hline Practical implementation and application & 56 & 23.2 & 40 & 21.7 & 10 & 40.0 & 6 & 18.8 \\
\hline $\begin{array}{l}\text { Promote connections to the learners' working } \\
\text { practice }\end{array}$ & 55 & 22.8 & 50 & 27.2 & 1 & 4.0 & 4 & 12.5 \\
\hline Enable transfer & 24 & 10.0 & 19 & 10.3 & 3 & 12.0 & 2 & 6.3 \\
\hline Feedback & 20 & 8.3 & 13 & 7.1 & 1 & 4.0 & 6 & 18.8 \\
\hline Total & 1172 & 100.0 & 806 & 100.0 & 190 & 100.0 & 176 & 100.0 \\
\hline
\end{tabular}


subcategories. The final category system is shown in Tables 5 and 6 . A detailed description of each subcategory and its definition is described later in the results.

The interviews were analyzed for all words or phrases that could be identified to provide information about intentions or strategies. The statements were then allocated to the corresponding subcategories. Coding units ranged from single words to whole paragraphs. If the content of a statement was connected to several categories or subcategories, multiple codings were possible. Phrases that were too broad or unspecific in their meaning were not coded. For example, "I want them to profit from the training", refers to a general intention but is too unspecific to be allocated to a concrete category with reference to our research question. Other examples include "we worked with various methods" or "learners were activated," which refer to some kind of strategy but are phrased too broadly to be allocated to any specific category.

To assure the quality of the category system and coding procedures, the research team discussed categories and coding continuously during the coding process until no more necessary changes emerged from the material. All interviews were then coded by a main coder. To assess intercoder reliability, approximately $50 \%$ of the interviews (12 trainers, 5 HRD practitioners, 6 trainees), selected according to the highest number of codings, were coded by two more coders. For the strategy category, coders allocated phrases within a category to a subcategory. For the intention category, coders allocated phrases to the main categories. Cohen's Kappa (Cohen 1960), which considers the number of categories coded, was separately calculated for all three coder pairs (AB, BC, AC). The average of all Kappa values per category was between .77 and $.84(M=.81)$. These values can be interpreted as acceptable when considering the low frequency of some categories and the high level of abstraction of other categories.

\section{Results}

The purpose of the analysis was to investigate whether the existing theoretical model (Trigwell et al. 1994) can be used to describe approaches to teaching in the field of professional training or whether the model must first be adjusted. Furthermore, we wanted to gain a deeper understanding of how each category can be described and defined for professional training to be able to operationalize the construct in future studies.

The final analysis counted 1404 codings across all interviews, $1172(83.5 \%)$ belonging to strategies and $232(16.5 \%)$ belonging to intentions. Of all codings, $978(69.7 \%)$ were found in interviews with trainers, $233(16.6 \%)$ were found in interviews with HRD practitioners, and $193(13.7 \%)$ were found in interviews with trainees. Although the frequency of the categories differed significantly by group, the ordinal rankings of the categories by each group were similar across the groups and with the aggregate ordinal ranking by all groups. An overview of all categories and subcategories, as well as their frequencies per group and across all interviews, is shown in Tables 5 and 6.

We first present our results on the intention category, followed by those on the strategy category. The descriptions of the categories depict the intentions and strategies that comprise the different approaches to teaching and how they are set in the training context. At the end of the results section, we present an analysis on overlapping categories. 


\section{Intention}

Intention includes statements that provide justification for the use of a strategy and statements that more generally describe what kind of goal should be achieved during training. All codings were allocated to one of the following five categories (see Table 5).

Statements referring to the category information transmission describe the aim of the trainers to impart knowledge during the training, which can be understood as a basic transfer of knowledge from one person to another without an anticipated higher level of understanding from the learner.

Concept acquisition consists of statements describing the aim of the trainers to explain the subject matter such that learners will not only receive knowledge but also truly understand it and make connections between different types of information.

The next category marks the transition from transmissive intentions to more constructive intentions. Conceptual development refers to statements describing the aim to provide learners with the opportunity to autonomously acquire knowledge and to find and develop solutions by themselves.

The category conceptual change mainly contains statements that refer to a deeper process of change, e.g., a change in behavior or an initiative toward self-development, that goes beyond the "pure" content of the training. This category was mainly found when interview partners were discussing the context of soft-skill trainings.

The inductively added intention category transfer comprises all statements that contain the goal of enabling and facilitating transfer into working practice.

\section{Strategy}

Strategy includes all statements that describe how the training is conducted and which actions the trainer takes during a training, including his or her methods. The codings were assigned to the following categories (see Table 6).

\section{Transmissive Strategies}

Transmissive strategy is trainer-oriented and focuses on transmitting or imparting knowledge. In this type of teaching, the learners take on a passive role. All codings of this category were assigned to one of the five following subcategories.

Transmissive methods are concrete methods through which the trainer imparts knowledge, such as lecturing, explaining or using media tools such as flipcharts and Power Point presentations.

Imparting knowledge comprises all general statements regarding transmitting knowledge, theory or content to learners that do not mention a concrete method.

Negative learner-orientation includes all statements describing the trainer as not being responsive to the learners' needs. The trainer conducts his or her training the way it was originally planned, even when the needs of the learners demand adjustment.

Trainer takes center stage as an expert includes statements that underline the role of the trainer as an expert with the ability to disseminate expert knowledge. The trainer, not the learner, is at the center of the training. 
No activating methods includes all statements that describe the learners as passive or as not activated. The trainer uses no activating methods.

\section{Interactive Strategies}

Interactive strategies are focused on trainers and learners and comprise every statement referring to a strategy that is based on an interaction between the trainer and the learner. Two subcategories were identified in the codings.

Interactive methods are concrete methods in which the trainer and the learners are equally involved. Such methods are mostly based on a dialectic format and include classroom discussions, open questions to the classroom and giving feedback to the learners.

Interactive teaching action refers to general statements that describe strategies based on an interaction between trainer and learner in which both parties are equally, actively involved, and do not mention a concrete method.

\section{Constructivist Strategies}

Constructivist strategies are learner-oriented and focus on providing learning opportunities in which the learner self-directedly constructs knowledge. This category can be described by the following six subcategories.

Constructivist methods refer to all concrete methods or methodological settings where learners are engaged with themselves or with other learners and which provide opportunities to acquire knowledge autonomously and to find and develop solutions by themselves. These methods can include exercises, individual or group work, role-play scenarios, project work, video feedback, discussion between learners, and feedback between learners.

Learner-orientation refers to all strategies that are based on the reactions or characteristics of learners or on needs directly mentioned by the learners. The trainer is sensitive to the learners' needs and may even actively ask them about their needs. He or she is flexible in adapting the order of the content or even adapting the content itself to the learners' needs if necessary. The training is in accordance with the learners' needs, and the learners are therefore placed at the center of the training.

The active learning category includes statements that do not refer to concrete methods but instead describe general constructivist strategies such as providing opportunities for learners to gain practical experience and to utilize or apply what they learned in the training.

The trainer as learning guide category includes statements that describe the active role of the trainer during the training as being supportive within the learning process and acting as a learning guide.

The self-reflection category comprises statements that describe the opportunity for self-reflection or for reflecting on lesson content at a meta-level.

The independently develop and acquire knowledge and solutions category includes statements that describe ways in which learners work independently during the training to acquire knowledge autonomously and find solutions by themselves. 


\section{Transfer-Facilitating Strategies}

Transfer-facilitating strategies are learner-oriented and refer to all strategies that enable transfer of the acquired knowledge and competencies into the working practice of the learners. This category can be further described using the following five subcategories. The subcategories are in line with what we know about transfer-facilitating methods from training research (e.g., Burke and Hutchins 2007; Grossman and Salas 2011; Salas et al. 2012).

Transfer-enabling methods are concrete methods that provide the opportunity for learners to obtain practical experience and to utilize or apply what they learned in the training. Examples of such methods include exercises, role-play activities, video feedback, games and/or case studies.

Practical implementation and application comprises all general statements that describe providing learners with the opportunity to obtain practical experience and to utilize or apply what they learned in the training, and do not name a concrete method.

Promote connections to the learners' working practice includes all statements that describe the trainer connecting the contents of the training with the working practice or the work environment using examples or exercises that are as similar as possible to real situations.

Enable transfer are general statements conveying that learners should be provided with the opportunities for transfer or for applying the learned knowledge to the learners' working practice.

Feedback refers to all statements in which the learners are provided with feedback either by the trainer or by other learners. Feedback, unlike, e.g., role play, is not a method in itself but either refers to a behavior or activity of the trainee or is part of a method, e.g., feedback after a role-play exercise. Thus, we created a separate category for transfer, as the literature on training research shows feedback to be an important tool to facilitate transfer (e.g., Burke and Hutchins 2007; Grossman and Salas 2011; Salas et al. 2012).

\section{Overlapping of Categories}

When coding interview material, it is possible that a sentence or phrase could contain aspects that refer to different categories. Thereby, the codings of two categories can overlap. By analyzing the occurrence of such overlaps, possible connections between categories can be identified. While most categories had 26 or fewer statements that overlapped with other categories, the transfer-facilitating strategy category $(N=241)$ overlapped 175 times $(72.6 \%)$ with the constructivist strategy category. The most overlaps were found between constructivist methods and transfer-enabling methods $(n=84)$ and between practical implementation and application and active learning $(n=47)$.

\section{Discussion}

The goals of our study were to investigate whether the approaches to teaching construct described by Trigwell et al. (1994) could be applied in the context of professional 
training or whether the construct would need adaptation and to analyze how best to describe individual theoretical categories for the future operationalization of the construct. Thus, we conducted 45 semistructured interviews with trainers, HRD practitioners and trainees to produce a multi-perspective view on their perceptions of approaches to teaching in trainings. Our results were analyzed with qualitative content analysis (Mayring 2014). Following our research objectives, we first discuss our findings on the overall concept of approaches to teaching in the professional context and then discuss our findings on intentions and strategies. We then discuss the limitations of our study and present our final conclusions and outlook for future studies.

\section{Approaches to Teaching in Professional Training}

All intention and strategy dimensions described by Trigwell et al. (1994) were identified in the interview material. We can therefore conclude that the theoretical model and its basic structure can indeed be used to describe approaches to teaching in a professional training setting. However, we found the additional transfer intention category and the additional transfer-facilitating strategy category. In our view, these additions reflect a major difference between the higher education and professional training contexts. The primary goal of professional training is the transfer of knowledge and behavior to the workplace. Finding the intention of transfer and the related transferfacilitating strategies in our interview material is thus in coherence with the nature of the professional training context. In future studies, it should be investigated whether the transfer-related categories should be included into the overall theoretical model of approaches to teaching in professional training. From a theoretical point of view, the addition of these categories would be consistent with a wide body of research highlighting the importance of transfer as an intention in the training context and the corresponding transfer-facilitating methods (e.g., Baldwin and Ford 1988; Burke and Hutchins 2008; Blume et al. 2010; Salas et al. 2012).

Trainer interviews had approximately four times more codings than HRD practitioner or trainee interviews. This finding could be explained by the different interview lengths for each group and by the differences in group size (10/12 vs. 23) or by the fact that the trainers are most engaged with the subject matter on an everyday basis and thus actively reflect on intentions and strategies while planning and conducting trainings. Although the frequencies of the categories are given, they should be interpreted with caution. However, the frequency of a category within the data might provide an indication of tendency on the perceived importance of a category to our interview partners. The ordinal ranking of the categories was similar among the groups and with the total ranking as well. Of note, some of the transmissive strategy codings are statements regarding negative examples of how not to conduct a training and therefore might present a bias in the interpretation of the number of codings for this category.

\section{Intentions and Strategies in Professional Training}

Regarding our second research objective, the descriptions of the categories and subcategories provide detailed insight into how each facet of these approaches to teaching can be described in the training setting. Apart from the addition of the transfer category, the intention category reflects the description proposed by Trigwell et al. (1994). 
However, the interview material added a new perspective on the category of conceptual change. The category description by Trigwell et al. (1994) refers to students changing their conception of a phenomenon within the studied discipline, thus having an epistemological focus. In our interviews, the statements relating to conceptual change mainly described trainees changing their behavior or taking further steps in their personal self-development. Therefore, we would broaden the definition of conceptual change for the professional training context. In addition to the epistemological-focused conceptual change, we would include a person-focused conceptual change. As training facilitates not only knowledge but also skills and attitudes (Salas et al. 2012), this extension of the definition reflects the aims of professional training.

Besides the addition of the transfer-facilitating category, the strategy category reflects the main structure proposed by Trigwell et al. (1994) but provides a much more detailed description of how transmissive strategies or constructivist strategies are implemented in the professional training setting. The subcategories of transferfacilitating strategy reflect what we know about transfer-facilitating methods from the training literature (e.g., Burke and Hutchins 2007; Grossman and Salas 2011; Salas et al. 2012). The transmissive strategy and constructivist strategy subcategories follow descriptions that can be found in teacher-oriented and student-oriented approaches in the literature (e.g., Kember 1997; Trigwell et al. 1994; Kember and Kwan 2002), but our subcategories are much more detailed and specific.

The interactive strategy category was the category with the lowest number of codings within the strategy category. For previous versions of the category system, the research team discussed whether some of the subcategories of the constructivist strategy category should or could also be allocated to the interactive strategy category. Although the interaction category as a middle category between transmissive and constructivist makes sense on a theoretical and conceptual basis, we found it difficult to unambiguously allocate some of the strategy subcategories to interactive or constructivist strategies based on our interview material. For example, the learner-oriented strategy category was assigned as a constructivist strategy category based on theoretical assumptions. However, it could also have been assigned to the interactive strategy category because some learner-oriented strategies also have interactive characteristics, such as actively asking learners about their needs or discussing with them the themes that should be covered during the training. From a methodological and a theoretical point of view, we finally chose to allocate it to the constructivist category, although arguments could be made for alternative solutions. This decision illustrates one of the challenges that lie at the heart of working with interview materials.

Regarding our long-term research goal of operationalizing approaches to teaching, we do not recommend operationalizing interactive strategies as an independent part of a scale because we do not expect them to be clearly discriminable from constructivist strategies. This conclusion was drawn from our results and is further supported by the documentation of the ATI development (Trigwell and Prosser 2004; Prosser and Trigwell 2006), in which the subscale interaction could not clearly be distinguished statistically from the constructivist subscale and thus was not included in the final version of the ATI.

The transfer-facilitating strategy category showed a high overlap with the constructivist strategy category. This overlap highlights the close relationship between the two categories. Both include the use of similar methods and an action-related or practice- 
related approach. Additionally, both have very similar category definitions, although they have different emphases. This similarity raises the question of whether constructivist strategies and transfer-facilitating strategies are independent from one another or whether transfer-facilitating strategies are instead a subset of constructivist strategies in professional training. In our current study, we formed a new category, parallel to the intention of transfer. Our explorative study can only provide a first indication for the emergence of the transfer theme. The relationship between transfer-facilitating strategies and constructivist strategies needs to be examined closely in future studies to decide whether the theme of transfer is an immanent part of constructivist strategies in professional training or if it is merely closely connected to them. When trying to operationalize these aspects of teaching approaches for future research, we would expect a substantive contentwise overlap between constructivist strategy and transferfacilitating strategy and a high correlation between both constructs.

\section{Limitations}

When conducting qualitative research, one must consider whether a deductive or inductive approach is appropriate for answering a research question. By building our category system within the framework of an already existing theory, there is the risk of reproducing theoretical structures. To minimize this risk, we used different strategies to achieve theoretical blindness. We worked in a research team where decisions and definitions were continually discussed and reevaluated. Though using a category system based on an existing theory, we remained open to the discovery of new phenomena, e.g., the newly identified categories regarding transfer. Additionally, the subcategories were developed in an explorative manner to be as open as possible within the analysis process.

Another potential point of criticism is that the analysis was conducted on interview material that was produced within a thematically wider study and that we used very open questions, following the principle of openness. Consequently, the questions were not drafted to animate the interview partners to explicitly describe intentions and strategies. This could have led to the smaller number of intention codings compared to the number of strategy codings, as intentions are of a more implicit nature than directly observable strategies. Furthermore, the narrow interview length of the trainee interviews needs to be critically assessed. Trainees can not be expected to reflect as intensely on trainings as interviewed trainers would do. Even so, interviewing techniques should be improved in future studies, e.g. by specifically activating memories on training experiences and more in depth interview questions when designing the interview guideline.

We conducted most interviews by telephone and only some face-to-face. Although Sturges and Hanrahan (2004) found no significant difference between the two interview modes, there could still have been effects on interviewer-interviewee interaction, communication patterns or interview length (Irvine et al. 2013). Despite these limitations, the interview material was extensive and provided a comprehensive foundation for analysis, as observed in the results of our study.

\section{Conclusion and Outlook}

To summarize, we can conclude that the concept of teaching approaches is applicable in the context of professional training. However, it should be modified by adding the 
aspect of transfer to the model. Additionally, possible context-specific differences in some of the category and subcategory descriptions should be considered. The detailed portrayals of the categories extend beyond the existing descriptions and definitions of approaches to teaching and thus provide a deeper understanding of transmissive and constructivist approaches to teaching. Our sample focuses on trainings within the field of professional training. Although we presume that our results and implications could be transferred to other sectors of adult education, such as trainings that are not job related, this hypothesis should be investigated in additional studies.

To understand the role of different approaches to teaching in professional training, studies should examine which kinds of intentions and strategies promote the best learning and transfer outcome. However, to study approaches to teaching in professional training, a valid and reliable measurement scale is needed. The most commonly used instrument to measure approaches is the ATI (Trigwell and Prosser 2004). The instrument was designed within the higher education context, with items referring to the specifics of this context, e.g., "In this subject, I only provide the students with the information they will need to pass the formal assessments". Hence, it cannot necessarily be transferred one-to-one to the context of professional training. To study approaches to teaching in professional training, a new measurement scale would need to be developed. The results of our analysis will provide a foundation for the operationalization of approaches to teaching in professional training and for the development of such a measurement scale.

\section{Funding Information Open Access funding provided by Projekt DEAL.}

Open Access This article is licensed under a Creative Commons Attribution 4.0 International License, which permits use, sharing, adaptation, distribution and reproduction in any medium or format, as long as you give appropriate credit to the original author(s) and the source, provide a link to the Creative Commons licence, and indicate if changes were made. The images or other third party material in this article are included in the article's Creative Commons licence, unless indicated otherwise in a credit line to the material. If material is not included in the article's Creative Commons licence and your intended use is not permitted by statutory regulation or exceeds the permitted use, you will need to obtain permission directly from the copyright holder. To view a copy of this licence, visit http://creativecommons.org/licenses/by/4.0/.

\section{References}

Baldwin, T. T., \& Ford, J. K. (1988). Transfer of training: A review and directions for future research. Personnel Psychology, 41(1), 63-105.

Baldwin, T. T., Ford, J. K., \& Blume, B. D. (2017). The state of transfer of training research: Moving toward more consumer-centric inquiry. Human Resource Development Quarterly, 28(1), 17-28.

Baumert, J., \& Kunter, M. (2013). The COACTIV model of teachers' professional competence. In M. Kunter, J. Baumert, W. Blum, S. Krauss, \& M. Neubrand (Eds.), Cognitive activation in the mathematics classroom and professional competence of teachers: Results from the COACTIV project (pp. 25-48). Boston, MA: Springer.

Blume, B. D., Ford, J. K., Baldwin, T. T., \& Huang, J. L. (2010). Transfer of training: A meta-analytic review. Journal of Management, 36(4), 1065-1105.

Braun, E., \& Hannover, B. (2008). Zum Zusammenhang von Lehr-Orientierung und Lehrgestaltung von Hochschuldozierenden und subjektivem Kompetenzzuwachs bei Studierenden [The relationship between teaching orientations and teaching design of higher education teachers and the subjectively perceived growth in competence of students]. In M. A. Meyer, M. Prenzel, \& S. Hellekamps (Eds.), Perspektiven 
der Didaktik (Zeitschrift für Erziehungswissenschaft: Special Issue 9, pp. 277-291). Wiesbaden: VS Verlag für Sozialwissenschaften.

Burke, L. A., \& Hutchins, H. M. (2007). Training transfer: An integrative literature review. Human Resource Development Review, 6(3), 263-296.

Burke, L. A., \& Hutchins, H. M. (2008). A study of best practices in training transfer and proposed model of transfer. Human Resource Development Quarterly, 19(2), 107-128.

Cohen, J. (1960). A coefficient of agreement for nominal scales. Educational and Psychological Measurement, 10(1), 37-46.

Fendler, J., \& Brauer, E. K. (2013). Können Studierende die Lehrkonzepte und das Lehrhandeln ihrer Dozierenden einschätzen? [are students qualified to evaluate the teaching approach and teaching activities of their teachers?]. Zeitschrift für Hochschulentwicklung, 8(3), 110-124.

Fendler, J., \& Gläser-Zikuda, M. (2013). Teaching experience and the "shift from teaching to learning". Zeitschrift für Hochschulentwicklung, 8(3), 15-28.

Grossman, R., \& Salas, E. (2011). The transfer of training: What really matters. International Journal of Training and Development, 15(2), 103-120.

Hochholdinger, S., \& Keller, I. (2015). Welche Zusammenhänge bestehen zwischen den affektiven Reaktionen von Trainingsteilnehmenden, der Lehrorientierung von Weiterbildungspersonal und Weiterbildungsinhalten? [How are trainee reactions affected by trainers' approaches to teaching and training content?]. Zeitschrift für Erziehungswissenschaften, 18(1), 123-144.

Irvine, A., Drew, P., \& Sainsbury, R. (2013). 'Am I not answering your questions properly?'clarification, adequacy and responsiveness in semi-structured telephone and face-to-face interviews. Qualitative Research, 13(1), 87-106.

Kember, D. (1997). A reconceptualisation of the research into university academics' conceptions of teaching. Learning and Instruction, 7(3), 255-275.

Kember, D., \& Kwan, K. (2002). Lecturers' approaches to teaching and their relationship to conceptions of good teaching. In N. Hativa \& P. Goodyear (Eds.), Teacher thinking, beliefs and knowledge in higher education (pp. 219-240). Dortrecht: Springer.

Könings, K. D., Seidel, T., Brand-Gruwel, S., \& van Merriënboer, J. J. (2014). Differences between students' and teachers' perceptions of education: Profiles to describe congruence and friction. Instructional Science, $42(1), 11-30$.

Laker, D. R., \& Powell, J. L. (2011). The differences between hard and soft skills and their relative impact on training transfer. Human Resource Development Quarterly, 22, 111-122.

Lindblom-Ylänne, S., Trigwell, K., Nevgi, A., \& Ashwin, P. (2006). How approaches to teaching are affected by discipline and teaching context. Studies in Higher Education, 31(3), 285-298.

Mayring, P. (2014). Qualitative content analysis: theoretical foundation, basic procedures and software solution. http://www.ssoar.info/ssoar/bitstream/handle/document/39517/ssoar-2014-mayring-Qualitative content_analysis_theoretical_foundation.pdf?sequence=1. Accessed 24 June 2019.

Murray, K., \& Macdonald, R. (1997). The disjunction between lecturers' conceptions of teaching and their claimed educational practice. Higher Education, 33, 331-349.

Prosser, M., \& Trigwell, K. (2006). Confirmatory factor analysis of the approaches to teaching inventory. British Journal of Educational Psychology, 76(2), 405-419.

Postareff, L., Lindblom-Ylänne, S., \& Nevgi, A. (2008). A follow-up study of the effect of pedagogical training on teaching in higher education. Higher Education, 56(1), 29-43.

Rosário, P., Núñez, J. C., Vallejo, G., Paiva, O., Valle, A., Fuentes, S., \& Pinto, R. (2014). Are teachers' approaches to teaching responsive to individual student variation? A two-level structural equation modeling. European Journal of Psychology of Education, 29(4), 577-601.

Salas, E., Tannenbaum, S. I., Kraiger, K., \& Smith-Jentsch, K. A. (2012). The science of training and development in organizations: What matters in practice. Psychological Science in the Public Interest, 13, 74-101.

Stes, A., \& Van Petegem, P. (2014). Profiling approaches to teaching in higher education: A cluster-analytic study. Studies in Higher Education, 39(4), 644-658.

Sturges, J. E., \& Hanrahan, K. J. (2004). Comparing telephone and face-to-face qualitative interviewing: A research note. Qualitative Research, 4(1), 107-118. 
Trigwell, K., \& Prosser, M. (2004). Development and use of the approaches to teaching inventory. Educational Psychology Review, 16(4), 409-424.

Trigwell, K., Prosser, M., \& Taylor, P. (1994). Qualitative differences in approaches to teaching first year university science. Higher Education, 27, 75-84.

Trigwell, K., Prosser, M., \& Waterhouse, F. (1999). Relations between teachers' approaches to teaching and students' approaches to learning. Higher Education, 37(1), 57-70.

Uiboleht, K., Karm, M., \& Postareff, L. (2018). The interplay between teachers' approaches to teaching, students' approaches to learning and learning outcomes: a qualitative multi-case study. Learning Environments Research, 21(3), 321-347.

Uiboleht, K., Karm, M., \& Postareff, L. (2019). Relations between students' perceptions of the teachinglearning environment and teachers' approaches to teaching: a qualitative study. Journal of Further and Higher Education, 43(10), 1456-1475.

Publisher's Note Springer Nature remains neutral with regard to jurisdictional claims in published maps and institutional affiliations.

Caroline Bonnes is a postdoctoral fellow at the Chair of Corporate Education at the University of Konstanz (Germany). She received her $\mathrm{PhD}$ in education at the Goethe University Frankfurt (Germany). Her main research interests are in professional education with a strong focus on the professional competence of trainers and training transfer.

Sabine Hochholdinger is professor at the Chair of Corporate Education at the University of Konstanz (Germany). She has a background in psychology, economics and educational sciences. Her research focuses on workplace learning and the professional competence of trainers 